\title{
STUDIES ON THE TOTAL COLUMN ATMOSPHERIC AEROSOL OPTICAL DEPTH, OZONE AND PRECIPITABLE WATER CONTENT IN THE TROPICS: A CASE STUDY OF MALAYSIA
}

\author{
Said Fhazli \\ Department of Physics, Faculty of Mathematic, Natural and Health Science, \\ Muhammadiyah University of Riau.
}

\begin{abstract}
Abstrak
A Multifilter Rotating Shadowband Radiometer has been used to monitor the directly transmitted solar irradiance at six wavelength regions $(413.9 \mathrm{~nm}, 494.6 \mathrm{~nm}, 612.7 \mathrm{~nm}, 670.8 \mathrm{~nm}, 868.0 \mathrm{~nm}$ and $939.1 \mathrm{~nm}$ ) for three clear stable days at Bangi. Extensive observations of the columnar aerosol optical depth (AOD), total column ozone (TCO) and precipitable water content (PWC) have been carried out using this instrument. The result shows that the maximum optical depth of aerosol at the shorter wavelength, especially on $24^{\text {th }}$ February 2002 with mean value of 0.254 $\left(24^{\text {th }}\right.$ February 2002), 0.095 (25 ${ }^{\text {th }}$ February 2002), and $0.072\left(26^{\text {th }}\right.$ February 2002) while the ozone optical depth shows the mean value 0.0153 on $24^{\text {th }}$ February $2002,0.0174$ on $25^{\text {th }}$ February 2002 and 0.0175 on $26^{\text {th }}$ February 2002 with the avarage absorption coefficient $(a), 0.2$ $\left(24^{\text {th }}\right.$ and $26^{\text {th }}$ February 2002) and $0.1\left(25^{\text {th }}\right.$ February 2002). The mean value of water vapor content shows that $\gamma=0.356 \mathrm{~cm}$ and $k=0.301 \mathrm{~cm}$ for wavelength $939.1 \mathrm{~nm}$. From the aerosol optical depth, it shows the existence of smoke type of aerosol on February, $24^{\text {th }}$ to $25^{\text {th }} 2002$ with Ångström coefficient, $\alpha$, is 1.534 and 1.5513 , respectively, and sea water vapor is 0.9889 on $26^{\text {th }}$ February 2002. From the Angström coefficient, it shows that atmosphere layer of Bangi at that moment is similar to U.S. Standard Atmosphere, with maximum spectral irradiance on black body temperature is $5860{ }^{\circ} \mathrm{K}$.
\end{abstract}

\section{INTRODUCTION}

The atmospheric pollutants such as aerosols, ozone and water vapor play important roles in the study of the Earth's climate system, because they directly interact with the solar radiation and modify the climate. Solar radiation is attenuated when passing through the earth's atmosphere. Therefore, solar radiation measured at the surface of the earth's depends on the amount of water vapor, ozone and mixed gases as well as the qualitative characteristics and concentration of aerosols. One of the important property to know the characteristics of atmospheric pollutants is optical thisckness which is affecting the transfer of radiant energy in the earth's atmosphere. There is a need to know the spectral characteristic of solar irradiances and the extent to which changes in environmental factors affect this energy distribution. In this article, the characteristic of atmospheric pollutants is investigated by means of series of measurements done at Bangi, Malaysia. Atmospheric optical properties such as optical depths, spectral transmittances are retrieved in order to establish some "background", characteristics of the atmospheric conditions over the Bangi atmosphere. Studies on this subject have been conducted by King et al (1977), Dani et al (1999) and Harris. J (1999). 


\section{EXPERIMENTAL SET-UP}

Studies on the total column atmospheric aerosol optical depth (AOD), total column ozone (TCO) and precipitable water content (PWC) have been conducted at Universiti Kebangsaan Malaysia, Bangi, Selangor, Malaysia (2 ${ }^{\circ} 55^{\prime}$ North, $101^{\circ} 50$ ' East) using Automated Multi Filter Rotating Shadowband Radiometer (MFRS). This instrument has been installed at the roof top of a building so that no sun ray obstruction by any objects in the hemisphere dome vision of the instrument. Figure 1 shows the experimental set-up of this instrumen. The observations were made from morning till evening (from 7 am till $5 \mathrm{pm}$ ) on the days when the sky was nearly free from visible clouds, and none were near the line-of-sight to the sun. The observations were repeated at an interval of about 20 seconds with average time arround 40 seconds when the air-mass changes rapidly during the post-sunrise and pre-sunset periods.

The MFRSR is a ground based instrument that use independent interference-filter photodiode detectors and the computer controlled automated rotating shadow-band technique to make spectrally resolved measurements at seven wavelengths of directnormal, total-horizontal, and diffusehorizontal irradiances. The three irradiances components are measured with the same detector for a given wavelength. The measurement sequence starts with a measurement made while the band is nadir; this is the total horizontal irradiance. The band is then rotated so that the three measurements are made in sequence. The middle one blocks the sun, to give the diffuse horizontal irradiance, and the other two block strips of the sky 90 to either side.

These side measurement allow for a first order correction for the excess sky blocked by the band when the sun-blocking measurement is made.Finally, it will use eq. 1 to calculate the direct normal component of solar irradiation.

$$
I_{\text {total }}=I_{\text {diffuse }}+\cos \left(\theta_{z}\right) I_{\text {direct }}
$$

The MFRS have 7 channels of measurements, except for channel 0 , each channel is sensitive for aerosol, Rayleigh, ozone and water vapour absorption. The complete range of solar spectrum measured from MFRS is listed in table below

\section{Table1. MFRS specifications}

\begin{tabular}{|c|c|c|c|}
\hline $\begin{array}{c}\text { Chann } \\
\text { el }\end{array}$ & $\begin{array}{c}\text { Waveleng } \\
\text { th }(\mathrm{nm})\end{array}$ & Bandwidth & Sensitivity to \\
\hline 0 & $\begin{array}{l}300- \\
1100\end{array}$ & Broadband & $\begin{array}{l}\text { Broadband } \\
\text { spectrum }\end{array}$ \\
\hline 1 & 413.9 & & $\begin{array}{l}\text { Aerosol/Rayl } \\
\text { eigh }\end{array}$ \\
\hline 2 & 494.6 & 9.8 & $\begin{array}{l}\text { Aerosol/Rayl } \\
\text { eigh/Ozone }\end{array}$ \\
\hline 3 & 612.7 & 10.7 & $\begin{array}{l}\text { Aerosol/Rayl } \\
\text { eigh/Ozone }\end{array}$ \\
\hline 4 & 670.8 & 10.6 & $\begin{array}{l}\text { Aerosol/Rayl } \\
\text { eigh/Ozone }\end{array}$ \\
\hline 5 & 868.0 & 11.8 & $\begin{array}{c}\text { Aerosol/Rayl } \\
\text { eigh }\end{array}$ \\
\hline 6 & 939.1 & 11.8 & Water Vapour \\
\hline
\end{tabular}

Figure 1. Experimental set-up and data measurement

\section{RETRIEVAL OF AOD, OZONE AND PRECIPITABLE WATER CONTENT}

The optical depth of the atmosphere can be determined from the Beer-Bouger-Lambert law, expressing attenuation $(\alpha)$ of the direct solar beam in the atmosphere in the form:

$$
I(\lambda)=I_{o}(\lambda) e^{-\tau_{t}(\lambda) m\left(\theta_{o}\right)},
$$

where $I(\lambda)$ is the monochromatic solar irradiance reaching the instrument detector at wavelength $\lambda ; I_{0}(\lambda)$ the irradiance incident on the top of the atmosphere ( $\tau=0$ level) and it can be used to self calibrate the system; $m\left(\theta_{o}\right)$ the atmospheric air mass, a function of solar zenith angle $\theta_{o}$; and $\tau_{t}(\lambda)$ the optical depth. Taking the natural logarithm of (2) yields 


$$
\operatorname{LnI}(\lambda)=\operatorname{LnI}_{o}(\lambda)-\tau_{t}(\lambda) m\left(\theta_{o}\right),
$$

and thus a plot of $\operatorname{LnI}(\lambda)$ vs $m\left(\theta_{o}\right)$ will yield a straight line of slope $-\tau_{t}(\lambda)$, and $y$-intercept of $\operatorname{LnI}_{o}(\lambda)$, assuming that the optical depth remains constant during the course of observations.

Because the number of air mass is range from 2 to 6 it is sufficient for us to calculate this value by using cosine zenith angle (Iqbal, 1983).

$m\left(\theta_{z}\right)=\frac{1}{\cos \theta_{z}}$

The number of air mass from 2 to 6 is corresponding to the position of the sun in the sky where the time series data were taken only from morning to local noon or local noon to afternoon. In our case only the morning till noon time series data were taken due to the cloudy and overcast sky condition in the afternoon.

Figure 2 illustrates a typical Langley plot $\left[\ln \mathrm{I}(\lambda)\right.$ vs $m\left(\theta_{o}\right)$ which has been obtained for Bangi at five wavelengths $(0.4139,0.4966$, $0.6127,0.6708$ and $0.8680 \mu \mathrm{m}$ ) on 24

February 2002. The lines drawn in Fig. 2 represent the best fit to the data in a least squares sense, with the resulting slopes being the negative of the total optical depths.

The total optical depth of the atmosphere is the sum of the optical depths of its individual components:

$\tau_{\text {tot } \lambda}=\tau_{o z \lambda}+\tau_{R \lambda}+\tau_{a \lambda}+\tau_{w v \lambda}$

From the values of total optical depth $\tau_{\text {tot } \lambda}$ and by assuming the water vapor absorption contributed to channel 6 equal to zero one can determine corresponding values of the aerosol optical depth, designated $\tau_{\mathrm{a} \lambda}$, for each day. This is obtained by subtracting from $\tau_{\text {tot } \lambda}$ the contribution due to molecular scattering $\tau_{R \lambda}$, known as the Rayleigh optical depth, and the contribution of the ozone
Chappuis absorption band $\tau_{o z} \lambda$, known as the ozone optical depth. Thus,

$\tau_{a \lambda}=\tau_{t o t \lambda}-\tau_{o z \lambda}-\tau_{R \lambda}$

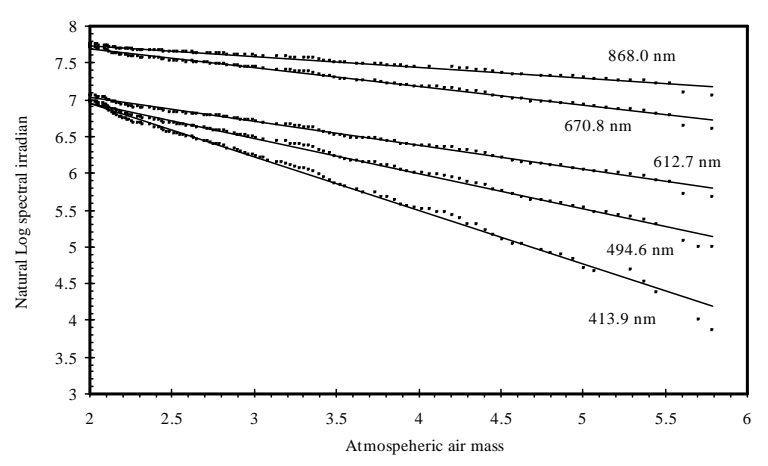

Figure 2. The linear relationship which exists between the log solar irradiance and the atmospheric air mass for stable conditions

The Rayleigh scattering optical depth is a function of surface pressure $P$, while the ozone optical depth is a function of total ozone content $\eta$ measured in atm- $\mathrm{cm}^{1}$ was estimated from the formula as below:

$\tau_{R \lambda}=\left(P / P_{o}\right) 0.008735 \lambda^{-4.08}$

$\tau \mathrm{oz}(\lambda, \eta)=\eta \mathrm{a}(\lambda)$

and thus (6) may be rewritten as

$\tau_{a}(\lambda, p, \eta)=\tau_{t o t}(\lambda)-\left(P / P_{o}\right) 0.008735 \lambda^{-4.08}$.

$-\eta \mathrm{a}(\lambda)$,

where $P$ is the barometric station pressure and $P_{o}=1013.25 \mathrm{hPa}$ and $a(\lambda)$ are the ozone absorption coefficients per centimeter of pure gas at STP.

The atmospheric turbidity parameters $\beta$ and $\alpha$ could be derived from the optical thickness due to aerosols $\left[\tau_{\mathrm{a}}(\lambda)\right]$ according to Ångström:

$\tau_{a \lambda}=\beta \lambda^{-\alpha}$

where $\beta$ is the "Ångström Tubidity coefficient" and $\alpha$ is the wavelength exponent which is closely associated to the size of the ${ }_{1}^{1} 1 \mathrm{~atm}-\mathrm{cm}=2.687 \times 10^{10}$ molecules-cm
column. 
scattering particles and the frequency of their distribution. We can alter the Angström Tubidity formula into a linear form by taking the logarithm (10)

$$
\ln \left(\tau_{a \lambda}\right)=\ln (\beta)-\alpha \ln (\lambda) \text {, thus }
$$

We can determine the value of $\alpha$ and $\beta$ by the value for aerosol optical depth for each wavelength in a linear regression. The result of this regression give us the species, concentration and transmittance of the aerosol contained in the atmosphere for that particular day.

King and Byrne (1976) who described a mathematical formulation whereby the $\mathrm{O}_{3}$ absorption optical depths, and hence total ozone content of the atmosphere, could be inferred from spectral variation of total optical depth in the visible and near-infrared wavelength regions. In the Chappuis bands outside of other gaseous absorption bands contributions of aerosols and ozone to total optical depth are the unknowns for each channel. Using the priori knowledge of the spectral behaviour of aerosol optical depth the ozone optical depth can be determined. The basic of this technique is described below:

Assuming a Junge size distribution of the form $n(r)=c r^{-v^{*}-1}$

where the radius $r$ extends from 0 to $\infty$ predicts that

$\tau_{a}=\beta \lambda^{-v^{*}+2}$

Note: this is Ångström's empirical formula for the wavelength dependence of aerosol optical depth (see equation 10). Taking the logarithm of (13), this equation becomes

$$
\begin{aligned}
\log \tau_{a} & =\log (\beta)-\left(v^{*}-2\right) \log \lambda \\
& =a_{0}+a_{1} \log (\lambda)
\end{aligned}
$$

which is linear when $\log \tau_{a}$ is plotted against $\log \lambda$.

In general the aerosol size distribution will neither be Junge nor have radii extending from 0 to $\infty$. Both non Junge size distribution and finite radii limits, introduce a slight curvature on a $\log \tau_{a}$ vs $\log \lambda$ plot instead of the linier dependence as implied by (14). Since (14) implies no curvature, a secondorder term was added, and the observations of $\log \tau_{a}(\lambda, P, \eta)$ calculated from (9) were fitted to a quadratic of the form

$\log \tau_{a}=a_{o}+a_{1} \log \lambda+a_{2}(\log \lambda)^{2}$,

in order to determine the total ozone content $\eta$ and the coefficient $a_{o}, a_{1}$ and $a_{2}$.

Maximizing the probability that the $\log$ $\tau_{\mathrm{a}}(\lambda, p, \eta)$ obsservations have the functional form of (14) is equivalent to minimizing the statistic $\chi^{2}$ defined as

$\chi^{2}=\sum_{i} \frac{1}{\sigma_{i}^{2}}\left[\begin{array}{l}\log k_{a \lambda}\left(\lambda_{i}, p, \eta\right)-a_{o} \\ a_{1} \log \lambda_{i}-a_{2}\left(\log \lambda_{i}\right)^{2}\end{array}\right]^{2}$

Minimizing $\chi^{2}$ as defined by (16) is equivalent to making a weighted least-squares fit to the data.

In determining the precipitable water vapor (PWV) we only use the channel 6 of MFRSR for wavelength 940-nm.

The basis for retrieving $u$ from measurements of the attenuation of the direct beam irradiance, relies on knowledge of the variation of transmission with $u$ over the 0.94 $\mu \mathrm{m}$ MFRSR channel, and correction for attenuation in this band due to aerosol and molecular scattering.

The modified Langley method was used to retrieve $u$ from MFRSR. The idea behind this method is to assume that the attenuation of the direct beam irradiance follows the Lambert-Beer-Bouguer law for aerosol and 
molecular scattering, and power law for water vapour absorption. Thus,

$$
r_{0.94}=r_{t, 0.94} \exp \left[-\tau_{s, 0.94} m-k(u m)^{\gamma}\right]
$$

where $r_{0.94}$ is the band integrated direct beam irradiance measured by the MFRSR, $r_{t, 094}$ is the (band integrated) top-of-atmosphere irradiance, $m$ is the airmass, $\tau_{s, o 94}$ is the optical depth due to aerosol and molecular scattering, $u$ is precipitable water, and $k$ and $\gamma$ are parameters to be determined.

Another, related method can be used to retrieve $u$ using direct beam irradiances from the $0.87 \mu \mathrm{m}$ (channel 5) and $0.94 \mu \mathrm{m}$ (channel 6) MFRSR. At $0.87 \mu \mathrm{m}$ it is assumed that there is negligible water vapour absorption within the band. Then,

$$
\mathrm{r} 0.87=\mathrm{rt}, 0.87 \exp [-\tau \mathrm{s}, 0.87 \mathrm{~m}] \ldots
$$

where $\tau_{s, 0.87}$ is the total optical depth (aerosol + molecular scattering) at $0.87 \mu \mathrm{m}$. If we assumed that,

$$
\tau \mathrm{s}, 0.94=\alpha \tau \mathrm{s}, 0.87
$$

where $\alpha$ is a constant, then combining (16)(18) yields, after manipulation

$$
\operatorname{Ln}\left[\left(\frac{r_{0.94}}{r_{0.87}^{\alpha}}\right) Q_{t}\right]=-k(u m)^{\gamma}
$$

$\mathrm{Qt}=\frac{\left(r_{t, 0.87}\right)^{\alpha}}{r_{t, 0.94}}$

$Q_{t}$ is aconstant factor for a given instrument (the earth-sun distance variation cancels out), depending only on the in-band solar extraterresterial irradiance and the factor $\alpha$

\section{RESULTS AND DISCUSSIONS}

The data obtained from Multifilter Rotating Shadowband Radiometer have been calculated. We choose three clear stable measurement representative data. The direct normal, global horizontal and diffuse horizontal spectra were measured on several occasions with the MFRSR.

Data on February, $24^{\text {th }}, 25^{\text {th }}$ and $26^{\text {th }}$ 2002 are suitable for Langley analysis due to their clear sky at the morning. These three days data have been filtered using objective algorithms proposed by Harrison et al (1994) and the points that remain are used for a final least-squares regression that yields the total spectral optical depth and extraterrestrial spectral irradiance.

The least-squares regression for three days time series data and the decomposition of the total optical depth for each wavelength

\begin{tabular}{|c|c|c|c|c|c|c|c|c|c|}
\hline Wavelength & Total & $\mathrm{P}^{2}$ & $\mathrm{Ln}$ & $\begin{array}{c}\text { Ozone } \\
\text { absorption }\end{array}$ & $\begin{array}{c}\text { Total } \\
\text { ozone }\end{array}$ & $\begin{array}{l}\text { Ozone } \\
\text { column }\end{array}$ & \multicolumn{3}{|c|}{ Optical depth } \\
\hline$[\mathrm{m}]$ & Depth & & & $(a)$ & $(\mathrm{atm}-\mathrm{cm})$ & (DU) & Rayleigh & Ozone & Aerosol \\
\hline 0.4139 & 0.7310 & 0.9949 & 8.3947 & 0.2374 & 1.2645 & 300.20 & 0.3194 & 0.0351 & 0.3765 \\
\hline 0.4946 & 0.4810 & 0.9959 & 7.8817 & 0.2211 & 0.6251 & 138.20 & 0.1544 & 0.0058 & 0.3208 \\
\hline 0.6127 & 0.3320 & 0.9810 & 7.6944 & 0.1967 & 0.2628 & 51.70 & 0.0645 & 0.0142 & 0.2533 \\
\hline 0.6708 & 0.2548 & 0.9723 & 6.8269 & 0.1722 & 0.2002 & 34.48 & 0.0445 & 0.0134 & 0.1969 \\
\hline 0.868 & 0.1450 & 0.9888 & 8.0237 & 0.1224 & 0.0825 & 10.10 & 0.0156 & 0.0079 & 0.1215 \\
\hline
\end{tabular}
yield as shown in tables below;

where,

Table 2: Total optical depth decomposition on $24^{\text {th }}$ February 2002 
Table 3: Total optical depth decomposition on 25th February 2002

\begin{tabular}{|c|c|c|c|c|c|c|c|c|c|}
\hline Wavelength & $\begin{array}{c}\text { Total } \\
\text { optical }\end{array}$ & $\mathrm{R}^{2}$ & $\begin{array}{c}\mathrm{Ln} \\
\left(\mathrm{I}_{0}\right)\end{array}$ & $\begin{array}{c}\text { Ozone } \\
\text { absorption }\end{array}$ & $\begin{array}{c}\text { Total } \\
\text { ozone } \\
\text { content }\end{array}$ & $\begin{array}{l}\text { Ozone } \\
\text { column }\end{array}$ & \multicolumn{3}{|c|}{ Optical depth } \\
\hline$[\mathrm{m}]$ & Depth & & & $(a)$ & $(\mathrm{atm}-\mathrm{cm})$ & (DU) & Rayleigh & Ozone & Aerosol \\
\hline 0.4139 & 0.4931 & 0.9906 & 8.2206 & 0.1502 & 2.0746 & 311.60 & 0.3194 & 0.0365 & 0.1372 \\
\hline 0.4946 & 0.2803 & 0.9946 & 7.7352 & 0.1160 & 1.2888 & 149.50 & 0.1544 & 0.0063 & 0.1196 \\
\hline 0.6127 & 0.1856 & 0.9903 & 7.5623 & 0.1122 & 0.5339 & 59.90 & 0.0645 & 0.0165 & 0.1046 \\
\hline 0.6708 & 0.1303 & 0.9913 & 8.0844 & 0.0827 & 0.5054 & 41.80 & 0.0445 & 0.0163 & 0.0695 \\
\hline 0.868 & 0.0709 & 0.9884 & 7.9678 & 0.0542 & 0.2657 & 14.40 & 0.0156 & 0.0112 & 0.0441 \\
\hline
\end{tabular}

Table 4: Total optical depth decomposition on 26th February 2002

\begin{tabular}{|c|c|c|c|c|c|c|c|c|c|}
\hline Wavelength & Total & & & $\begin{array}{c}\text { Ozone } \\
\text { absorption }\end{array}$ & $\begin{array}{l}\text { Total } \\
\text { ozone }\end{array}$ & $\begin{array}{l}\text { Ozone } \\
\text { column }\end{array}$ & & aticol de & \\
\hline$[\mathrm{m}]$ & Depth & & & (a) & (atm-cm) & (DU) & Rayleigh & Ozone & Aerosol \\
\hline 0.4139 & 0.4416 & 0.9991 & 8.0751 & 0.1130 & 2.7850 & 314.70 & 0.3194 & 0.0368 & 0.0854 \\
\hline 0.4946 & 0.2499 & 0.9985 & 7.6457 & 0.0908 & 1.6652 & 151.20 & 0.1544 & 0.0063 & 0.0892 \\
\hline 0.6127 & 0.1663 & 0.9989 & 7.4980 & 0.0876 & 0.7021 & 61.50 & 0.0645 & 0.0169 & 0.0849 \\
\hline 0.6708 & 0.1188 & 0.9957 & 8.0373 & 0.7190 & 0.0590 & 42.40 & 0.0445 & 0.0165 & 0.0578 \\
\hline 0.868 & 0.0696 & 0.9867 & 7.9455 & 0.0527 & 0.2732 & 14.40 & 0.0156 & 0.0112 & 0.0428 \\
\hline
\end{tabular}

$\ln \left(\mathrm{I}_{\mathrm{o}} \lambda\right)$ is $\ln$ ( uncalibrated extraterrestrial direct-normal irradiance)
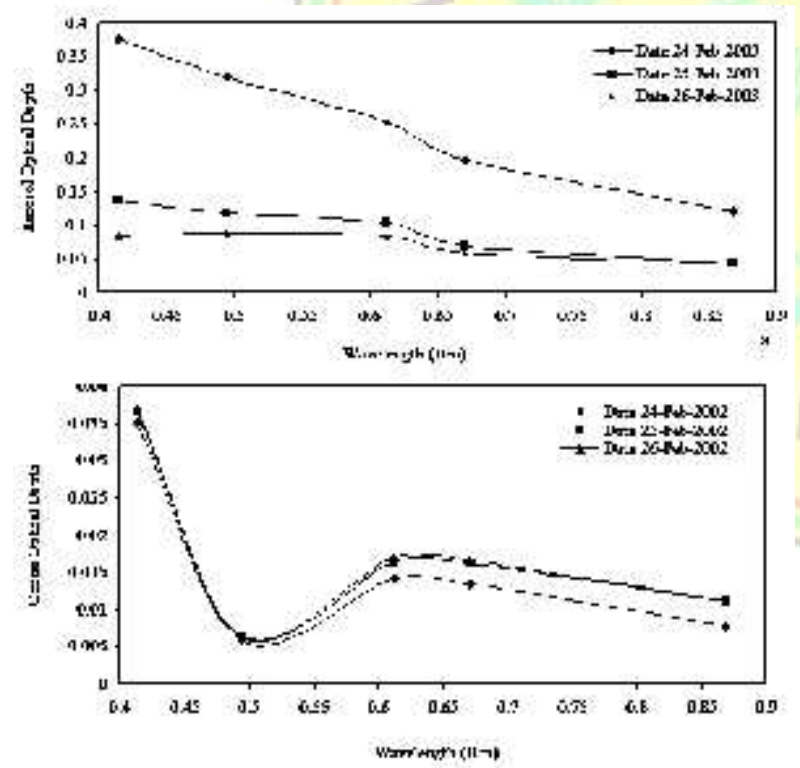

Figure 3. Spectral-temporal variation in (a) AOD, (b) TCO, observed on three clear days

The temporal variations in total AOD at different optical channels of the radiometer and total column ozone are shown plotted in figure 3 as separate frames (a) and (b). The frame (a) depicts time variations of AOD at different wavelength which clearly indicates more or less a systematic spectral dependence according to classical Mie scattering theory except at the NIR wavelengths. These features can be ascribed to the abundance of fine aerosol particles of continental origin that might have transported from land to oceanic region.

From frame (b), the ozone optical depth also showed gradual increase in the morning hours and decrease towards evening hours with a broad maximum during the afternoon hours, which can be explained on the basis of photochemistry.

Tables 5 displays the mean spectral dependence of AOD and corresponding aerosol size distribution observed on three clear stable days. The spectral variation of 
AOD exhibits high AOD at smaller wavelength and vice-versa. This shows the decrease of concentration for bigger suspended particle. The aerosol concentration distribution for each wavelength is shown in table below;

Table 5: Aerosol Concentration

\begin{tabular}{cccccc}
\hline \multicolumn{2}{c}{$24^{\text {th }}$ February 2002} & \multicolumn{2}{c}{$25^{\text {th }}$ February 2002} & \multicolumn{2}{c}{$26^{\text {th }}$ February 2002} \\
\hline $\begin{array}{c}\text { Optical } \\
\text { depth }\end{array}$ & $\begin{array}{c}\text { Concentration } \\
{\left[\mathrm{g} / \mathrm{m}^{3}\right]}\end{array}$ & $\begin{array}{c}\text { Optical } \\
\text { depth }\end{array}$ & $\begin{array}{c}\text { Concentration } \\
{\left[\mathrm{g} / \mathrm{m}^{3}\right]}\end{array}$ & $\begin{array}{c}\text { Optical } \\
\text { depth }\end{array}$ & $\begin{array}{c}\text { Concentration } \\
{\left[\mathrm{g} / \mathrm{m}^{3}\right]}\end{array}$ \\
\hline 0.3765 & 48.8676 & 0.1372 & 31.4131 & 0.0854 & 27.6292 \\
0.3208 & 44.8055 & 0.1196 & 30.1279 & 0.0892 & 27.9047 \\
0.2533 & 39.8809 & 0.1046 & 29.0352 & 0.0849 & 27.5951 \\
0.1969 & 35.7646 & 0.0695 & 26.4734 & 0.0578 & 25.6173 \\
0.1215 & 30.2680 & 0.0441 & 24.6178 & 0.0428 & 24.5229 \\
\hline
\end{tabular}

From the modified Langley method for retrieving precipitable water content (PWC) at 940-nm channel yields the parameter $k$ and $\gamma$ as shown in table 6. By using the linier regression, the result shows that there is a little variation of precipitable water vapour through the day and that it is reasonable to assume that the precipitable water vapour measured at Bangi is representative of the precipitable water at all other times during the daylight hours.

To determine the species of the aerosol particle, the Angström Tubidity formula is used to yields the Ångström Tubidity coefficient $\beta$ and wavelength exponent $\alpha$. This can be done by linear regression between wavelengths and aerosol optical depths. The results of this linear regression is shown in the table 7 .

Table 6 The results of linier regression on Precipitable water (equation 19)

\begin{tabular}{cccc}
\hline Date & $\mathrm{R}^{2}$ & $\gamma$ & $\mathrm{k}$ \\
\hline $24 / 02 / 2002$ & 0.9982 & 0.3624 & 0.3243 \\
$25 / 02 / 2002$ & 0.9951 & 0.3515 & 0.2617 \\
$26 / 02 / 2002$ & 0.9987 & 0.3541 & 0.3357
\end{tabular}

Table 7 The results of linier regression on Ångström Turbidity formula

\begin{tabular}{cccc}
\hline Date & $\alpha$ & $\beta$ & $\mathrm{R}^{2}$ \\
\hline $24 / 02 / 2002$ & 1.534 & 0.1248 & 0.9634 \\
$25 / 02 / 2002$ & 1.5513 & 0.0689 & 0.9115 \\
$26 / 02 / 2002$ & 0.9889 & 0.046 & 0.7656 \\
\hline
\end{tabular}

The results of table 7 above give us an indication that there are smoke and a mix of smoke and sea water vapour during the measurement. This is true where $\alpha$ is bigger than 1.4 for smoke from forest fire (for $24^{\text {th }}$ to $25^{\text {th }}$ February 2002) and for $\alpha$ between 1 to 1.4 is for a mix of smoke from fossil fuel burning and sea water vapour. In fact at that moment of measurement, there were a forest fire around the area due to the dry season. Finally, the average visibility calculated from the data analysis is $28.7 \mathrm{~km}$

\section{CONCLUSION}

The results of the analysis of optical data collected using the Multi-Filter Rotating Shadowband Radiometer indicate the following:

a. Spectral dependence of AOD with higher values at smaller wavelengths and viceverca. Greater values of AOD in the 
beginning and ending of the days when the air-mass exchange takes place.

b. There is a little variation of precipitable water vapour through the day of experiment and that it is reasonable to assume that the precipitable water vapour measured at Bangi is representative of the precipitable water at all other times during the daylight hours.

From the result data give an indication that there are smoke and a mix of smoke and sea water vapour during the measurement. These can be proved by the Angstrom parameters.

\section{REFERENCE}

Dani, K. K., Maheskumar R. S., \& Devara P. C. 1999. Study of total column atmospheric aerosol optical depth, ozone and precipitable water content over Bay of Bengal during BOBMEX-99. Earth planet science 112 (2): 205 - 221.

Harris, J. 1999. Measurement of aerosol over Santa Barbara with the Multi-Filter Rotating Shadowband Radiometer (MFRSR) (atas talian). http//:www.Ices.ucsb.edu/esrg/ess_sum97/ student_es.1999/harris/report_harris.html. (09 November 2001).

Harrison, L. \& Michalsky, J. 1994. Objective algorithms for the retrival of optical depth from ground measurements. Applied optics. 33(22): 5126-5132.

Harrison, L. Michalsky, J. \& Berndt, J. 1994b. Automated multifilter rotating shadow-band radiometer: an instrument for optical depth and radiation measurements. Applied optics.33(22): 5118-5125.

Hilburn, K. A. 2000. Turbidity at Mauna Loa (online). $\quad \mathrm{http} / / \mathrm{www} . c o a p s . f s u . e d u / \sim$ hilburn/report/turbml.pdf. (27 Desember 2002).

Iqbal, M. 1983. An Introduction to solar radiation. Toronto: Academic Press.

Kambezidis, H. D., Katevatis, E. M., Petrakis, M., Lykoudis, S. \& Asimakopoulos, D. N. 1998. Estimate of the Linke and Unsworth-Monteith turbidity factors in the visible spectrum: application for Athens, Greece. Solar energy. 62 (1):39-50.

King, M. D. \& Byrne, D. M. 1976. A method for inferring total ozone from the spectral variation of total optical depth obtained with a solar radiometer. Atmospheric science. 33(11): 2242-2251.

King, M. D., Byrne, D. M., Herman, B. M. \& Reagan, J. A., 1978. Aerosol size distribution obtained by inversion of spectral optical depth measurement. Atmospheric science. 35(11): 2153-2166.

King, M. D., Byrne, D. M., Herman, B. M. \& Reagan, J. A., 1980. Spectral variation of optical depth atmosfera Tucson, Arizona between August 1975 aand December 1977. Applied Meteorology. 19(6): 724732.

Mohd. Yusof. Hj. Othman., Kamaruzzaman Sopian., Baharuddin Yatim. \& Mohd. Nor Dalimin. 1993. Data bank: Diurnal pattern of global radiation in the tropics: a case study in Malaysia. Renewable energy. 3(6/7): 741-745.

Prata, A. J. 2000. Precipitable water retrieval from Multi-Filter rotating shadowband radiometer. CSIRO atmospheric research technical paper 47 (online). http//:www.dar.csiro.au/publications/prata _2000b.pdf. (10 January 2002).

Vermote, E. \& Kilcoyne, H. 2001. Suspended matter: Visible/infrared imager/radiometer suite algorithm theoretical basic document (online). http://npoesslib.ipo.noaa.gov/ atbd/viirs/Y2390-SusMatter-ATBD-4.pdf. (01 February 2002). 